\title{
CALCULATION OF SURFACE MO'TIONS OF A LAYERED HALF-SPACE
}

\author{
By N. C. Tsat and G. W. Housner
}

ABSTRACT

\begin{abstract}
A new method is presented for computing the transient response of a set of horizontally stratified, linearly elastic layers overlying a uniform half-space and excited by vertically incident, transient plane waves. In addition, a simple approximate method of satisfactory accuracy is developed that reduces the computing time required. Calculated responses are compared with motions recorded under Union Bay in Seattle to evaluate the agreement between recorded and calculated motions.
\end{abstract}

\section{INTRODUCTION}

The motion near the surface of the ground during an earthquake is of primary engineering significance in that it governs the vibratory response of most structures. Consequently it has been of much interest to engineers to investigate the influence of local geology on the surface motion. Inasmuch as the seismic waves travel through the Earth from the causative fault to the surface site they will be influenced by the properties of the geological materials through which they pass. The important engineering questions are: under what conditions will the effects of these geological influences be sufficiently prominent to be of practical significance, and can pre-earthquake calculations make satisfactory predictions of these effects? Attention has been directed mainly to the influences of surface layers as soft alluvial deposits seem usually to have the most pronounced effects on the surface motion.

The general problem of the passage of seismic waves through materials near the surface of the Earth is complicated by the nonuniform nature of the materials and of the seismic waves themselves. In some cases the influence of soft surface deposits has been observed to be very pronounced, for example, the spectrum of the motion recorded in Mexico City (Zeevaert, 1964) on the very soft ground that was formerly the bed of a lake showed a pronounced peak at a relatively long period of 2.5 sec. This coincides with the computed period of the fundamental mode of vibration of the lake bed as a bowl of jelly. The epicenter of the earthquake was relatively distant so that the bowl of jelly was responding primarily to the passage of horizontally traveling waves. A period of 2.5 sec corresponds to a half wavelength of about 2.5 miles which is sufficiently long for in-phase excitation of an extensive mass of soil. On the other hand, had the natural period of the lake bed been very short, the corresponding seismic wavelengths would have been too short, presumably, to produce appreciable excitation at the natural period of vibration.

If the site is relatively close to the causative fault, the surface deposits may be excited by essentially vertically-traveling waves. In this case the extent of the wave front as compared to the lateral extent of the deposits will have a strong influence. Usually the properties of surface layers, both elastic and geometric, are only poorly defined for a site. Also the nature of the seismic waves, both wave front and direction of travel, are not well known. Because of these difficulties analyses have not been made of real problems but, instead, a highly simplified problem has been studied. Sezawa and Kanai (1930, 1932 and 1935) first considered this problem of a system consisting of horizontally stratified layers overlying a homogeneous half-space and excited by 
vertically-traveling, plane, shear waves; each layer being homogeneous, isotropic and linearly elastic. This idealized, layered system has also been used for various subsequent studies. It has also been applied to the analysis of a vibrating building on an elastic foundation (Luco, 1969).

The use of the idealized, layered system reduces the problem from one of soil mechanics to one of the mechanics of a linear continuum of simplest geometry excited by the simplest waves. This simple layered system accentuates the influence of the "geological" properties in that any deviations from it would tend to lessen the influences, that is, if the individual layers were not homogeneous and linearly elastic, the layer interfaces not parallel, the seismic waves not planar, and not propagating vertically, the effect would be to attenuate most of the influences of the layered system upon the surface motion that are of engineering significance.

A procedure for digital computer calculation of the response of a simple layered system should include accurate methods of accounting for the energy lost by the passage of waves from the layers into the underlying half-space and for the energy lost while a wave is propagating within a layer. These requirements have caused some difficulty, for example, in some cases calculations have been made treating the underlying half-space as being infinitely rigid, with special damping introduced into the layers to make approximate allowance for the energy that should be lost into the half-space. In this paper a method of calculation is developed that accounts for the energy lost from the system and gives very accurate calculated responses. In addition, a simplified method of calculation is developed that reduces significantly the required computer time and yet gives results of satisfactory accuracy.

A proposed freeway in the city of Seattle was planned to pass beneath Union Bay in a tube imbedded in the soft clay layer underlying the bay. This posed certain problems of earthquake design and one of the authors served as consultant on this aspect of the project. To obtain information on the response of the clay layer to earthquake excitation, three geophones were installed at different depths, one in the clay layer, one in the underlying firm glacial till, and one in the top layer of peat. The records obtained from this system provide an opportunity to check how well the analysis of a simple layered system agrees with actual recorded motions. It is thought that Union Bay is almost ideal for such comparisons in that the layered system is very simple and the soil is very soft, both of which properties tend to make the influence of the layers stand out clearly. In addition, the distance between geophones is relatively small which is favorable to agreement between measurements and calculations.

\section{Analysis of the Layered System}

By considering an infinite train of harmonic waves as input the steady-state response of a layered system can be computed, from which an amplification spectrum, defined as the ratio of the steady-state amplitude of the surface response to that of the incident wave, can be constructed. The amplification spectrum indicates precisely the frequency-selective property of a layered system. However, steady-state analysis is not always sufficient for studying the effect of a layered system on earthquake-like excitation because actual earthquake motion is not steady-state and, hence, a transient analysis may be required that will exhibit the details of the motion. A well-known technique for finding the transient response of a layered system is to compute the system transfer function in the frequency domain. The Fourier transform of the input motion when multiplied by the transfer function, produces the Fourier transform of 
the output. An inverse transformation then gives the time history of the output, but Trorey (1962) has found that a poor digital inversion is obtained unless a small-size frequency interval is used. Baranov and Kunetz (1960) developed a useful ray-tracing technique that considers the successive reflection and transmission of a wave signal along each of the layer interfaces and gives the exact system response directly in time domain. A drawback of the ray-tracing technique is that it does not apply to viscoelastic layered systems because of the frequency dependence of the reflection and transmission coefficients in this case. Whitman (1968) and Idriss and Seed (1967) have used a lumped-mass model on an infinitely rigid half-space to calculate the surface motion.

The simple, layered system excited by vertically-traveling, plane waves is described by the same differential equation of motion as the so-called "shear-beam" which

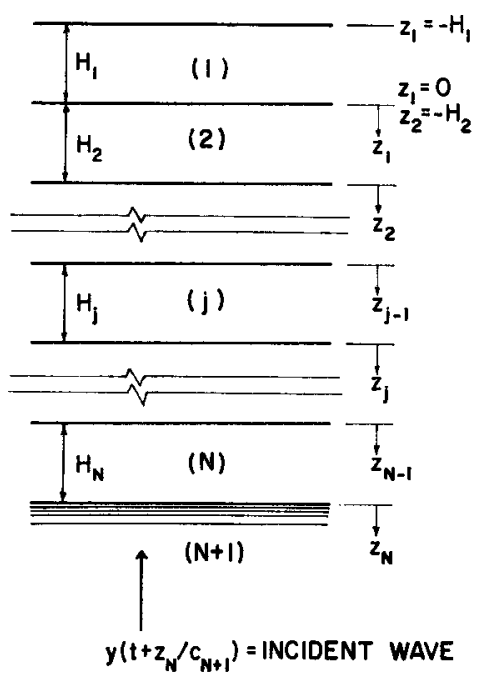

FIG. 1. The layered system.

undergoes shearing deformations only and, in fact, a vertical, square column abstracted from the layered system can be thought of as being the analogous shear-beam model. As it is somewhat easier to talk about and to visualize the motion of a beam, the following discussion will be in terms of a shear-beam model and $S$-wave motion. The results can be converted readily to those of $P$-wave motion by replacing the corresponding elastic and viscous constants.

\section{Transfer Function of a Layered System}

A layered system consisting of $N$ homogeneous, isotropic, and linearly elastic layers overlying a homogeneous half-space will be considered, as shown in Figure 1. The layers may be either viscoelastic or nonviscous, but the half-space foundation is taken to be nonviscous with no loss of generality. A set of $N$ coordinates, $z_{1}, \cdots, z_{N}$, is defined as shown. Let $H_{j}$ and $\rho_{j}$ be the thickness and the density, respectively, of the $j^{\text {th }}$ layer. A vertically incident, plane $S$-wave is described by $y\left(t+z_{N} / c_{N+1}\right)$ and the particle motion in the half-space is $y(t)$, with $c_{N+1}$ being the wave velocity in the half-space. Let $u_{j}\left(z_{j}, t\right)$ be the motion in the $j^{\text {th }}$ layer. For steady-state motion the governing equation for a linearly viscoelastic layered system is 


$$
c_{j}^{2}(\omega) \frac{\partial^{2} u_{j}}{\partial z_{j}^{2}}=\frac{\partial^{2} u_{j}}{\partial t^{2}} \quad j=1, \cdots, N
$$

in which $c_{j}(\omega)$ is the complex $S$-wave velocity. Let

$$
s_{j}=k_{j} H_{j}
$$

where

$$
k_{j}=\omega / c_{j}(\omega)
$$

is the wave number. The impedance ratio between the $j^{\text {th }}$ and $j+1^{\text {th }}$ layers is

$$
\alpha_{j}=\frac{\rho_{j} c_{j}(\omega)}{\rho_{j+1} c_{j+1}(\omega)}
$$

Note that $c_{j}$, and hence $k_{j}, s_{j}$, and $\alpha_{j}$, are real if the layered system is nonviscous. The following recursion formulas (Tsai, 1969) give the steady-state solution for $u_{j}\left(z_{j}, t\right)$.

$$
\begin{gathered}
\operatorname{Re}_{1}=1 \quad \text { and } \quad \operatorname{Im}_{1}=0 \\
\left\{\begin{array}{l}
\operatorname{Re}_{j}=\operatorname{Re}_{j-1} \cos s_{j-1}-\operatorname{Im}_{j-1} \sin s_{j-1} \\
\operatorname{Im}_{j}=\alpha_{j-1}\left(\operatorname{Im}_{j-1} \cos s_{j-1}+\operatorname{Re}_{j-1} \sin s_{j-1}\right)
\end{array}\right.
\end{gathered}
$$

such that

$$
u_{j}\left(z_{j}, t\right)=2 \operatorname{AMP}(\omega) G_{j}(\omega) \cos \left[k_{j}\left(H_{j}+z_{j}\right)+\Phi_{j}\right] e^{i\left(\omega t-\Phi_{N+1}\right)}
$$

where

$$
\begin{aligned}
\operatorname{AMP}(\omega) & =\frac{1}{\sqrt{\operatorname{Re}_{N+1}^{2}+\operatorname{Im}_{N+1}^{2}}}, \\
G_{j}(\omega) & =\sqrt{\operatorname{Re}_{j}^{2}+\operatorname{Im}_{j}^{2}},
\end{aligned}
$$

and

$$
\Phi_{j}=\tan ^{-1} \frac{\operatorname{Im}_{j}}{\operatorname{Re}_{j}}
$$

The quantities, $\operatorname{Re}_{j}$ and $\operatorname{Im}_{j}$, for a viscoelastic system are complex, in which case $\operatorname{AMP}(\omega), G_{j}(\omega)$, and $\Phi_{j}$ are also complex. In equation $(7), \operatorname{AMP}(\omega)$ is the amplitude ratio between the surface response $u_{1}\left(-H_{1}, t\right)$ and the input function $2 y(t)$, and is called the amplification spectrum of the layered system. By definition, the transfer function for $u_{j}$ with respect to $2 y(t)$ is 


$$
H_{j}(\omega)=\operatorname{AMP}(\omega) G_{j}(\omega) \cos \left[k_{j}\left(z_{j}+H_{j}\right)+\Phi_{j}\right] e^{-i \Phi_{N+1}}
$$

Let $H_{N}(\omega)$ be the transfer function for the base motion, $u_{N}(o, t)$. From equations (5), $(8)$, and (9),

$$
H_{N}(\omega)=\operatorname{AMP}(\omega) \operatorname{Re}_{N+1}(\omega) e^{-i \Phi_{N+1}}
$$

The transfer function for $u_{j}$ with respect to $u_{N}(o, t)$ will then be

$$
\begin{aligned}
H_{j, N}(\omega) & =H_{j}(\omega) / H_{N}(\omega) \\
& =\frac{G_{j}(\omega)}{\operatorname{Re}_{N+1}(\omega)} \cos \left[k_{j}\left(z_{j}+H_{j}\right)+\Phi_{j}\right] .
\end{aligned}
$$

Equation (11) implies that $H_{j, N}(\omega)$ is independent of the properties of the half-space foundation.

\section{The Shear Beam Model}

The shear-beam model consists of a shear beam connected at its base to the excitation $2 y(t)$ through a viscous dashpot $D$, as shown in Figure 2. The dashpot has a damping coefficient equal to $\rho_{N+1} c_{N+1}$ and can be shown to be an exact analog of the half-space by demonstrating that both the model and the layered system have the same transfer function, $H_{j}(\omega)$.

According to Figure 2, the equation of motion for the dashpot $D$ is

$$
\rho_{N+1} c_{N+1}\left[\dot{u}_{N}(o, t)-2 \dot{y}(t)\right]+\sigma_{N}(o, t)=0
$$

where $\sigma_{N}(o, t)$ is the shearing stress along the base interface. For steady-state motion the base stress can be expressed in terms of $u_{N}(o, t)$.

$$
\sigma_{N}(o, t)=-u_{N}(o, t) \frac{\omega \rho_{N+1} c_{N+1} \operatorname{Im}(\omega)}{\operatorname{Re}_{N+1}(\omega)}
$$

Substituting equation (13) into equation (12) shows that the model has a transfer function for $u_{N}(o, t)$ which is the same as the transfer function $H_{N}(\omega)$ given in equation 10. This result, together with the observation that both the shear beam and the original layered system have the same transfer function, $H_{j, N}(\omega)$, implies that the shear-beam model is an exact analog of a set of linearly viscoelastic layers overlying an elastic half-space. To compute the response of the model to an arbitrary input function, either the method of lumped masses may be used or, as is done in this paper, a method of modal analysis may be developed which considers the modal properties of the continuous shear beam and, hence, can achieve better accuracy. Moreover, as will be seen later, this method provides simple formulas for parameters such as natural frequencies, modal participating factors, etc. For purposes of exposition, the case of a nonviscous layered system and the case of a viscoelastic layered system will be discussed separately.

(1) Model for a nonviscous system. Let $x_{j}\left(z_{j}, t\right)$ be the relative motion of the $j^{\text {th }}$ layer with respect to the base.

$$
u_{j}\left(z_{j}, t\right)=x_{j}\left(z_{j}, t\right)+u_{N}(o, t)
$$


Thus, letting $c_{j}$ be the $S$-wave velocity in the nonviscous layered system, the equation of motion of the shear beam is

$$
c_{j}^{2} x_{j}^{\prime \prime}=\ddot{x}_{j}+\ddot{u}_{N}(o, t) \quad j=1, \cdots, N
$$

where the double prime stands for $\partial^{2} / \partial z_{j}{ }^{2}$ and the double dot for $\partial^{2} / \partial t^{2}$. By applying the appropriate boundary conditions, the solution of the homogeneous form of equation (15) yields the equation for computing the natural frequencies of the shear beam.

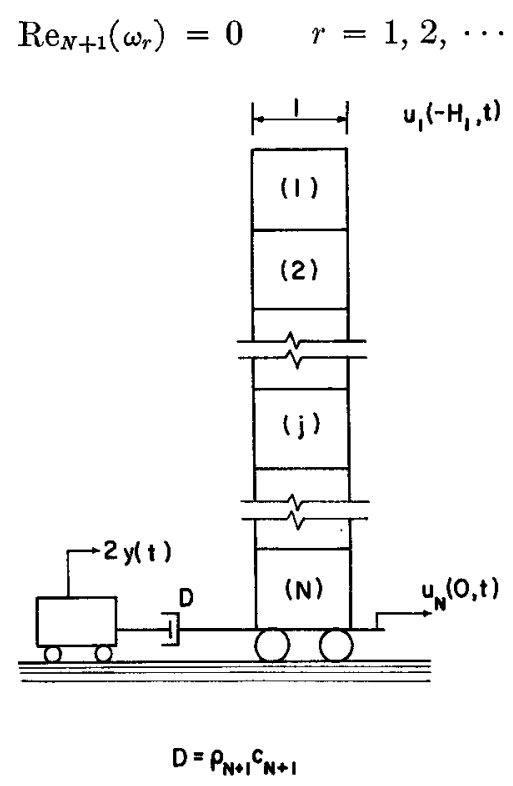

FIG. 2. The shear-beam model.

The mode shape in the $j^{\text {th }}$ layer is given by

$$
Z_{j}\left(\omega_{r}, z_{j}\right)=G_{j}\left(\omega_{r}\right) \cos \left[k_{j}\left(\omega_{r}\right)\left(z_{j}+H_{j}\right)+\Phi_{j}\left(\omega_{r}\right)\right]
$$

The modal shape functions are orthogonal to each other with respect to the density weighting function. A sufficient number of modes must be included in the analysis to give the required accuracy. Let this number be $S$ so that the $S$-mode solution of equation 15 can be written

$$
x_{j}\left(z_{j}, t\right) \approx \sum_{r=1}^{S} D_{r}^{(j)}\left(z_{j}\right) v_{r}(t)
$$

in which $D_{r}{ }^{(j)}$ is the modal participating factor given by (Tsai 1969)

$$
D_{r}^{(j)}\left(z_{j}\right)=\frac{2 \rho_{N+1} c_{N+1} \operatorname{Im}_{N+1}\left(\omega_{r}\right) Z_{j}\left(\omega_{r}, z_{j}\right)}{\omega_{r} \sum_{j=1}^{N} G_{j}{ }^{2}\left(\omega_{r}\right) \rho_{j} H_{j}}
$$

and $v_{r}(t)$ is the normal coordinate satisfying the following system of coupled modal equations. 


$$
\left\{\begin{array}{l}
\ddot{v}_{r}(t)+\omega_{r}^{2} v_{r}(t)=-\ddot{u}_{N}(o, t) \quad r=1, \cdots, S \\
\rho_{N+1} c_{N+1}\left[\dot{u}_{N}(o, t)-2 \dot{y}(t)\right]+\sigma_{N}(o, t)=0
\end{array}\right.
$$

The $S$-mode expression for the base stress in Equation (20b) can be shown to be

$$
\sigma_{N}(o, t) \approx-\sum_{r=1}^{S}\left(K_{\mathrm{eq}}\right)_{r} v_{r}(t)
$$

with

$$
\left(K_{\theta \mathrm{q}}\right)_{r}=\frac{2 \rho_{N+1}^{2} c_{N+1}^{2} \operatorname{Im}_{N+1}^{2}\left(\omega_{r}\right)}{\sum_{j=1}^{N} G_{j}^{2}\left(\omega_{r}\right) \rho_{j} H_{j}}
$$

In equation $(21),\left(K_{\text {eq }}\right)_{r}$ can be interpreted as the equivalent spring stiffness of a single-degree-freedom oscillator that represents the $r^{\text {th }}$ mode of the shear beam and has an equivalent mass

$$
\left(m_{\mathrm{eq}}\right)_{r}=\left(K_{\mathrm{eq}}\right)_{r} / \omega_{r}^{2} .
$$

Equation (20b) suggests that it is more convenient to treat the input motion as a velocity function, $2 \dot{y}(t)$, and to compute the velocity response, $\dot{u}_{j}$, as given by

$$
\dot{u}_{j}\left(z_{j}, t\right)=\sum_{r=1}^{S} D_{r}^{(j)}\left(z_{j}\right) \dot{v}_{r}(t)+\dot{u}_{N}(o, t)
$$

After being reduced to a system of $2 \mathrm{~S}+1$ first order differential equations, equation (20) can be solved by a technique of step-by-step numerical integration on a digital computer. An appropriate $S$ is selected by requiring that the $S$-mode transfer function agree satisfactorily with the exact solution in the frequency range of practical interest. Let the $S$-mode transfer function for the base motion be $\bar{H}_{N}(\omega)$. It can be shown that (Tsai 1969),

$$
\bar{H}_{N}(\omega)=e^{-i \Psi(\omega)}\left[1+Y^{2}(\omega)\right]^{-1 / 2}
$$

where

$$
\begin{aligned}
Y(\omega) & =\frac{1}{\omega \rho_{N}+1 C_{N}+1} \sum_{r=1}^{S} \frac{\left(K_{\mathrm{eq}}\right)_{r} \Omega_{r}{ }^{2}}{1-\Omega_{r}{ }^{2}} \\
\Omega_{r} & =\omega / \omega_{r}
\end{aligned}
$$

and

$$
\Psi(\omega)=\tan ^{-1}[Y(\omega)]
$$

The $S$-mode transfer function for $u_{j}$ is then given by

$$
\bar{H}_{j}(\omega)=\bar{H}_{N}(\omega)\left[1+\sum_{r=1}^{S} \frac{D_{r}^{(j)}\left(z_{j}\right) \Omega_{r}{ }^{2}}{1-\Omega_{r}{ }^{2}}\right]
$$


We take 0 to $60 \mathrm{rad} / \mathrm{sec}$ as the range of frequencies of greatest practical interest, and let $\omega_{1}, \cdots, \omega_{J}$ be the natural frequencies within this range. Numerical calculations indicate that a number $S$ chosen according to the following formula

$$
S \approx 2 J
$$

will yield satisfactory accuracy. To demonstrate the accuracy, a four-layer system $(N=4)$ is considered, for which the parameters are listed in Table 1 , columns 1 to 5 . The number $J$ was found to be 7 , and $S$ was taken to be 13 . The 13-mode amplitude transfer functions, $\left|\bar{H}_{1}(\omega)\right|$ and $\left|\bar{H}_{N}(\omega)\right|$, for the surface response and the base response, respectively, are shown by solid curves in Figures 3, (a) and (b); and the corresponding exact solutions are shown in dashed curves. Note that $\left|H_{1}(\omega)\right|$ is identical with the amplification spectrum, $\operatorname{AMP}(\omega)$, defined by equation (7). With the contributions from the first 13 modes taken into account, excellent accuracy is achieved in the prescribed range of frequencies. The accuracy of the analysis increases with the number $S$ but, for a fixed $S$, decreases with frequency.

TABLE 1

Layer Parameters for the 4-Layer System

\begin{tabular}{|c|c|c|c|c|c|c|}
\hline 1. Layer No. & $\begin{array}{c}\text { 2. Layer } \\
\text { Thickness } \\
H_{j}(\mathrm{ft})\end{array}$ & 3. Density & $\begin{array}{c}\text { 4. S-Wave } \\
\text { Volocity } \\
c_{j} \text { (fps) }\end{array}$ & 5. $\alpha_{j}$ & 6. $\tau_{j}^{*}(\mathrm{sec})$ & 7. $r_{j}^{*}$ \\
\hline 1 & 200 & 100 & 1000 & 0.385 & 0.005 & 1 \\
\hline 2 & 150 & 120 & 2400 & 0.658 & 0.002 & 5 \\
\hline 3 & 175 & 125 & 3500 & 0.720 & 0.0015 & 10 \\
\hline 4 & 225 & 135 & 4500 & 0.506 & 0.001 & 20 \\
\hline Half-space & & 150 & 8000 & & 0. & 100 \\
\hline
\end{tabular}

* For standard linear solids.

An earthquake-type motion of 2-sec duration, shown in Figure 4(a), was taken as the input function and the exact solution of the surface response, shown in Figure 5(a), was computed by means of the ray-tracing technique. To obtain the $S$-mode solution, equation (20) was solved numerically on an IBM 7094 digital computer. The result, shown in Figure 5(b), is in excellent agreement with the exact solution. This is expected because of the good accuracy of the $S$-mode transfer function. There is observed a general amplification of 2 to 3 in the surface motion.

By treating both the input and output as accelerations, the velocity response spectra, $S_{v}$, were computed as shown in Figures 6, (a) and (b), with the significant periods of the system, $T_{1}, \cdots, T_{7}$, marked in the output spectrum. The large hump around $\mathrm{T}_{1}$ in the output spectrum is obviously due to a strong response of the fundamental mode. On the other hand, it is concluded that the hump around $\mathrm{T}_{2}$ in the output spectrum is due to strong frequency components in the input motion because a similar hump appears on the input spectrum.

The $S$-mode base response is shown in Figure $4(\mathrm{~b})$. Unlike the surface response, the base motion more nearly resembles the input motion. Theoretically, as the value of the base impedance ratio, $\alpha_{N}$, approaches zero the base transfer function will approach unity and the base motion will approach $2 y(t)$. In practical problems $\alpha_{N}$ will be different from zero, and the error in taking $2 y(t)$ to be the base motion will be proportional to $\alpha_{N}$. 
(a)
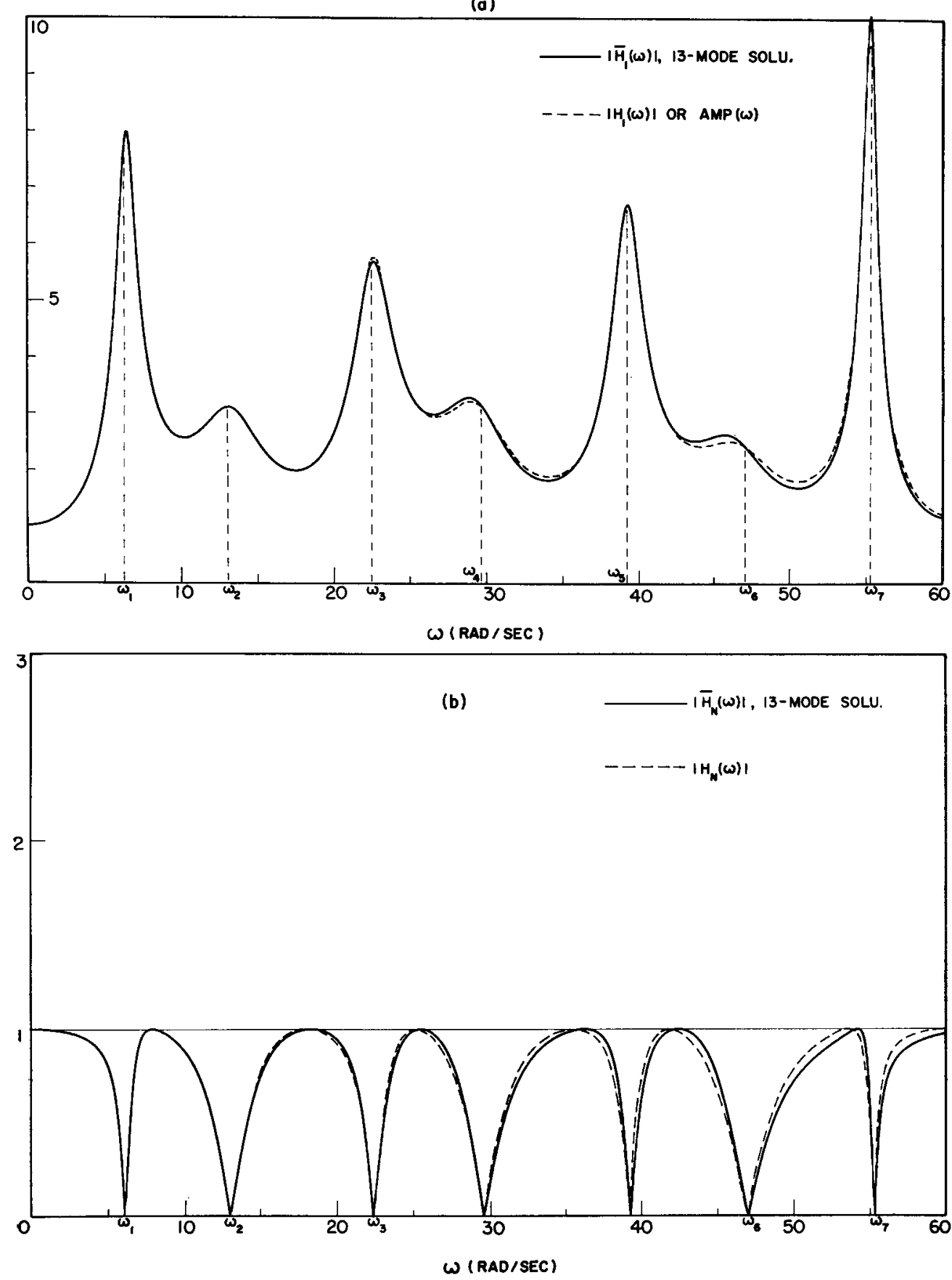

Fig. 3. The 13-mode amplitude transfer functions of the exact model (nonviscous system).

(2) Model for a viscoelastic layered system. For a linearly viscoelastic layered system the effect of viscosity must be included in the analysis and, therefore, a certain fraction of critical damping, $\beta_{r}$, is introduced into each of the modal equations of equation (20) which now has the following form 


$$
\left\{\begin{array}{l}
\ddot{v}_{r}(t)+2 \beta_{r} \omega_{r} \dot{v}_{r}(t)+\omega_{r}^{2} v_{r}(t)=0 \quad r=1, \cdots, S \\
\rho_{N+1} c_{N+1}\left[\dot{u}_{N}(o, t)-2 \dot{y}(t)\right]+\sigma_{N}(o, t)=0 .
\end{array}\right.
$$

The modal dampings are determined by requiring the $S$-mode amplitude transfer function $\left|\bar{H}_{1, N}(\omega)\right|$, to be matched with the exact transfer function, $\left|H_{1, N}(\omega)\right|$, at each of the first $S$ natural frequencies.
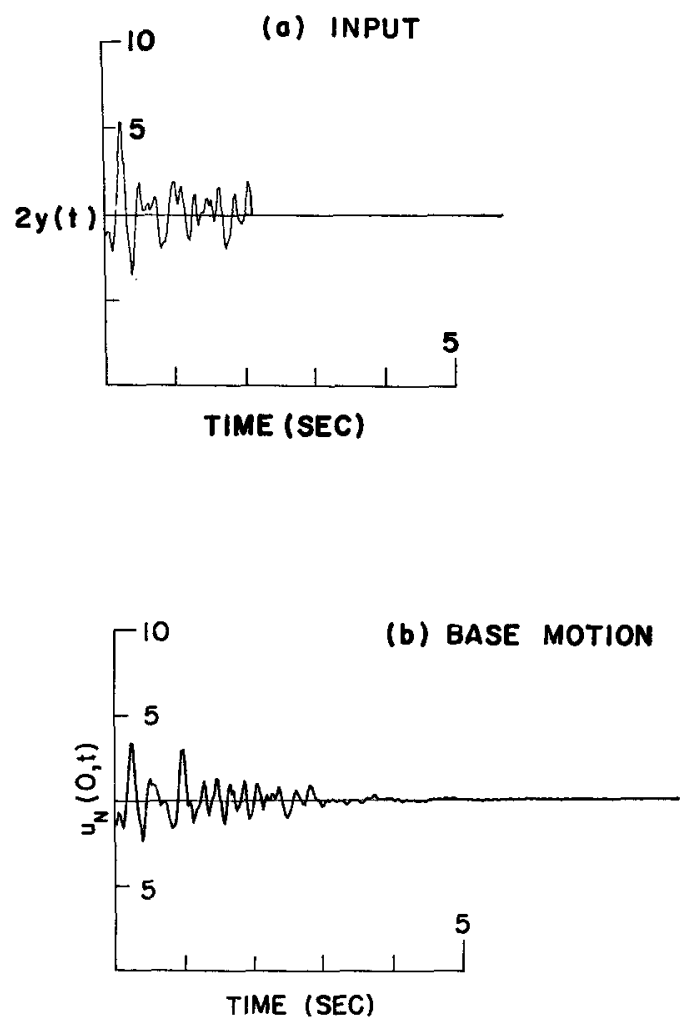

FIg. 4. The input function and the 13-mode base motion computed from the exact model.

$$
\left|H_{1, N}\left(\omega_{r}\right)\right|=\left|\bar{H}_{1, N}\left(\omega_{r}\right)\right| \quad r=1, \cdots, S
$$

$\left|\bar{H}_{1, N}(\omega)\right|$ is derived as follows. Assuming a steady-state base motion, $u_{N}(o, t)=e^{i \omega t}$, equation (29a) gives the steady-state response

$$
v_{r}(t)=X_{r} e^{i\left(\omega t-\theta_{r}\right)}
$$

where

$$
X_{r}=\frac{\Omega_{r}^{2}}{\sqrt{\left(1-\Omega_{r}^{2}\right)^{2}+\left(2 \beta_{r} \Omega_{r}\right)^{2}}}
$$

and

$$
\theta_{r}=\tan ^{-1}\left(\frac{2 \beta_{r} \Omega_{r}}{1-\Omega_{r}^{2}}\right)
$$


Hence, from equation (24),

$$
\begin{aligned}
\left|\bar{H}_{1, N}(\omega)\right| & =\left\{\left[1+\sum_{r=1}^{S} D_{r}^{(1)} X_{r} \cos \theta_{r}\right]^{2}\right. \\
& \left.+\left[\sum_{r=1}^{S} D_{r}^{(1)} X_{r} \sin \theta_{r}\right]^{2}\right\}^{1 / 2}
\end{aligned}
$$
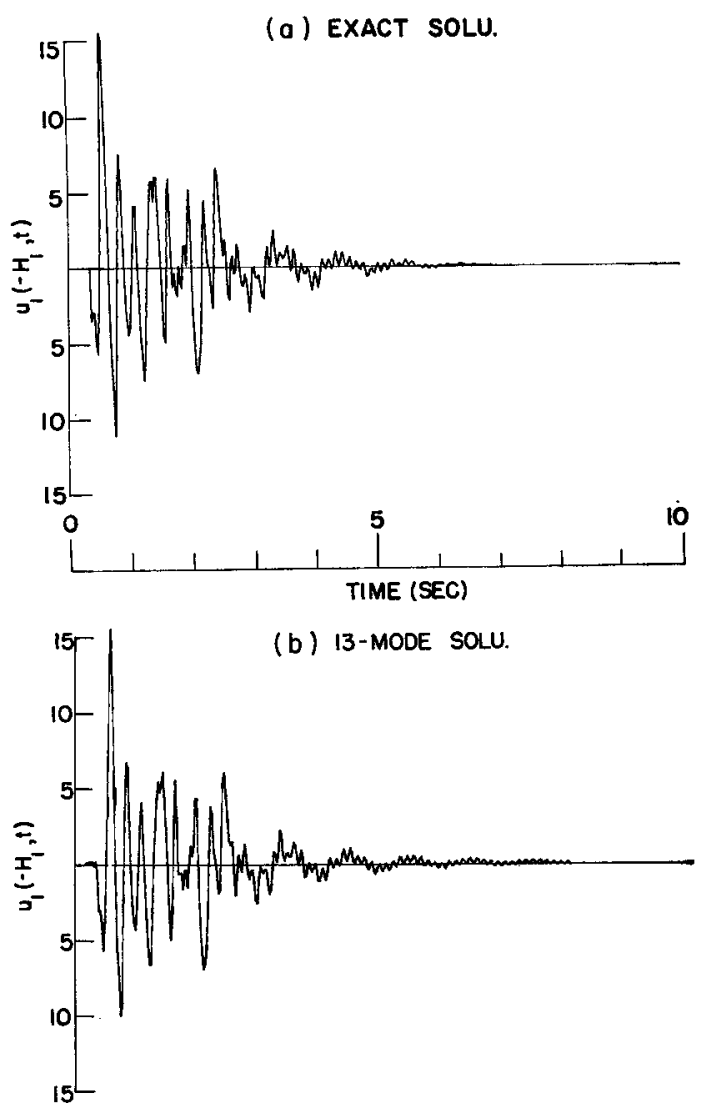

FIG. 5. Exact solution and 13-mode solution of the computed surface motion.

Since equation (39) is a nonlinear function of the unknowns $\beta_{r}$, equation (30) will be solved by a technique of iteration. A suitable initial value, $\left(\beta_{r}\right)_{o}$, for starting the iteration can be obtained by neglecting the contributions to $\left|\bar{H}_{1, N}\left(\omega_{r}\right)\right|$ from all modes other than the $r^{\text {th }}$ mode itself, i.e.,

$$
\left|\bar{H}_{1, N}\left(\omega_{r}\right)\right| \approx \frac{D_{r}^{(1)}}{2\left(\beta_{r}\right)_{0}} r=1, \cdots, S
$$

which, when substituted into equation (30), gives

$$
\left(\beta_{r}\right)_{o}=\frac{D_{r}^{(1)}}{2\left|H_{1, N}\left(\omega_{r}\right)\right|} .
$$


The iteration process can then be carried out to obtain modal dampings of any desired accuracy. The process converges very rapidly, and 3 to 5 iterations will usually yield results with a maximum iterative error within 1 per cent.

With the modal dampings determined, $\sigma_{N}(o, t)$ can be derived. First an equivalent

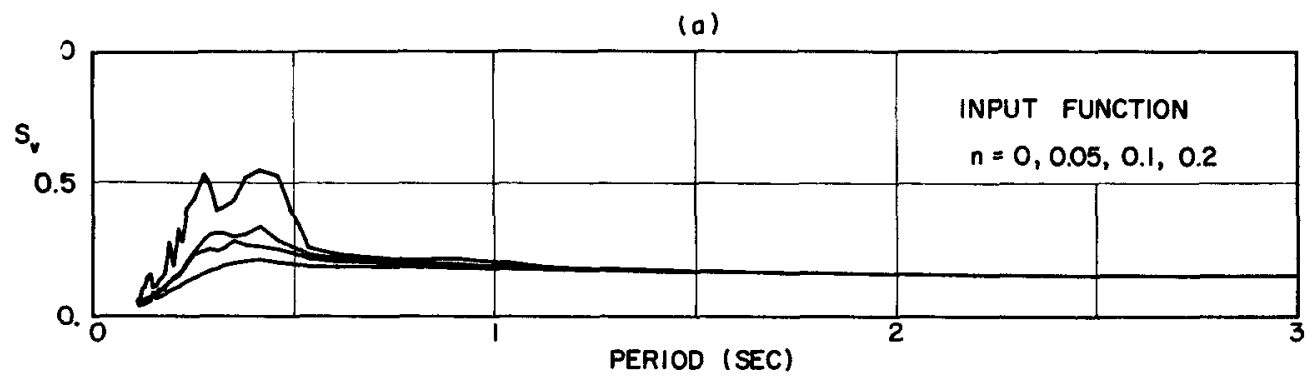

(b)

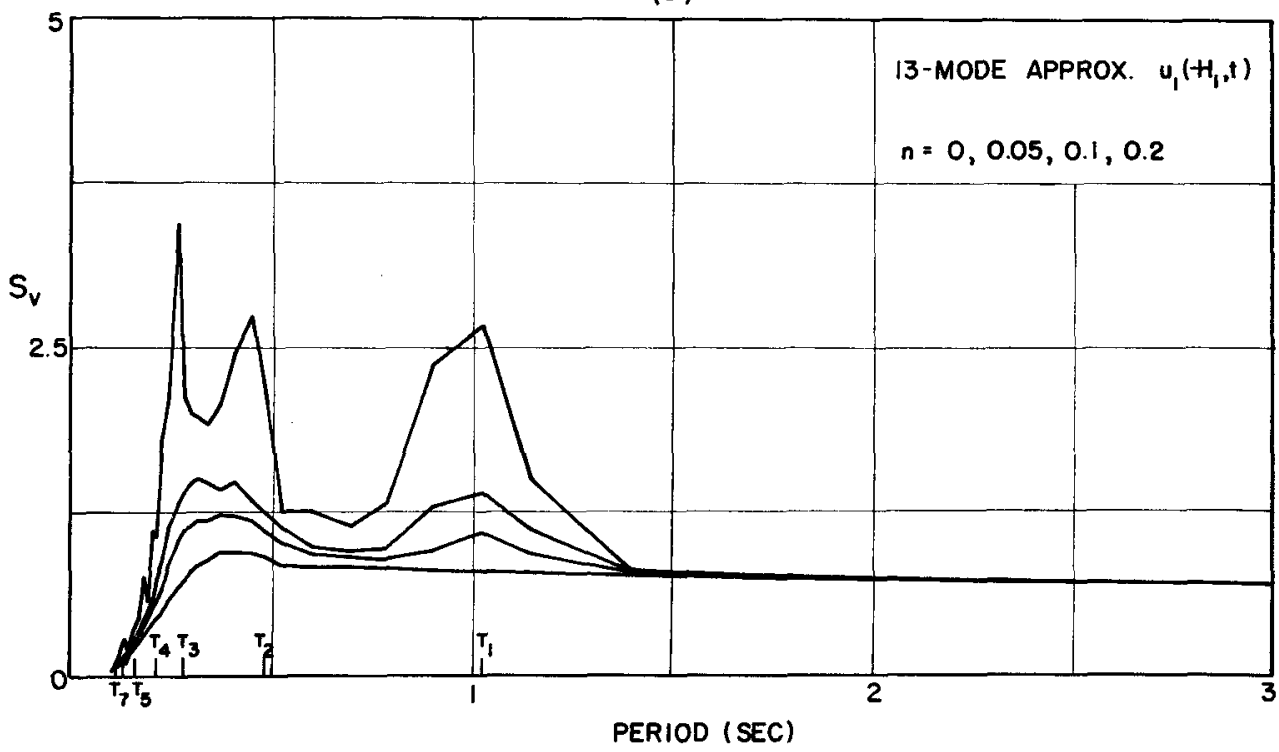

Fig. 6. Response spectra of the input motion and the 13-mode surface motion.

damping coefficient, $\left(C_{\text {eq }}\right)_{r}$, is introduced in the same manner that $\left(m_{\mathrm{eq}}\right)_{r}$ and $\left(K_{\mathrm{eq}}\right)_{r}$ were introduced in equations $(22)$ and $(23)$.

$$
\left(C_{\mathrm{eq}}\right)_{r}=2 \beta_{r} \omega_{r}\left(m_{\mathrm{eq}}\right)_{r}
$$

Hence,

$$
\sigma_{N}(0, t) \approx-\sum_{r=1}^{S}\left[\left(C_{\mathrm{eq}}\right)_{r} \dot{v}_{r}(t)+\left(K_{\mathrm{eq}}\right)_{r} v_{r}(t)\right]
$$

Equation (29) can now be solved for any desired response. To demonstrate the ac- 
curacy of the analysis the $S$-mode amplitude transfer function, $\left|\vec{H}_{1}(\omega)\right|$, is derived by first finding the function $\left|\bar{H}_{N}(\omega)\right|$. By using Equations $(29 \mathrm{~b}),(31)$, and (36),

$$
\left|\bar{H}_{N}(\omega)\right|=\frac{1}{\sqrt{B_{R}^{2}(\omega)+\overline{B_{I}^{2}(\omega)}}}
$$

in which

$$
B_{R}=1+\frac{1}{\omega \rho_{N+1} c_{N+1}} \sum_{r=1}^{S} X_{r}\left[\left(K_{\mathrm{eq}}\right)_{r} \sin \theta_{r}-\omega\left(C_{\mathrm{eq}}\right)_{r} \cos \theta_{r}\right]
$$

and

$$
B_{I}=\frac{1}{\omega \rho_{N+1} C_{N+1}} \sum_{r=1}^{S} X_{r}\left[\left(K_{\mathrm{eq}}\right)_{r} \cos \theta_{r}+\omega\left(C_{\mathrm{eq}}\right)_{r} \sin \theta_{r}\right]
$$

with $X_{r}$ and $\theta_{r}$ defined in equation (32). Thus,

$$
\left|\bar{H}_{1}(\omega)\right|=\left|\bar{H}_{1, N}(\omega)\right|\left|\bar{H}_{N}(\omega)\right|
$$

where $\left|\bar{H}_{1, N}(\omega)\right|$ was given by equation (33).

As a numerical example, the four-layer system considered before is assumed to be composed of standard linear solids, the basic structure of which is a spring, $\mu_{a}$, connected in series with an element consisting of a spring, $\mu_{b}$, and a dashpot, $\eta$, in parallel. For the $j^{\text {th }}$ layer let

$$
r_{j}=\left(\mu_{a}\right)_{j} /\left(\mu_{b}\right)_{j}
$$

and

$$
\tau_{j}=\eta_{j} /\left(\mu_{b}\right)_{j}
$$

Data for $r_{j}$ and $\tau_{j}$ are given in columns 6 and 7 of Table 1. The half-space is assumed nonviscous. The model dampings listed in column 2 of Table 2 have a maximum iterative error of 1 per cent.

The 13-mode solutions, $\left|\bar{H}_{1}(\omega)\right|$ and $\left|\bar{H}_{N}(\omega)\right|$, are shown together with their exact counterparts (Tsai, 1969) in Figures 7 (a) and 7 (b) respectively, and these indicate that the accuracy is sufficient in the prescribed frequency range. Using the input function shown in Figure $4(\mathrm{a})$, the computed surface response is shown in Figure 8(a). Although an exact solution is not available for comparison, the computed response can be expected to possess the same degree of accuracy as was obtained for the nonviscous system. The velocity response spectrum of the surface motion is shown in Figure 8(b) which clearly illustrates the effect of layer viscosity in damping the spectrum curves at higher frequencies. The large hump around the fundamental natural period, however, is little affected. It may be noted that the more damping there is in the layers the fewer the number of modes that need to be included for the same accuracy. 
(a)
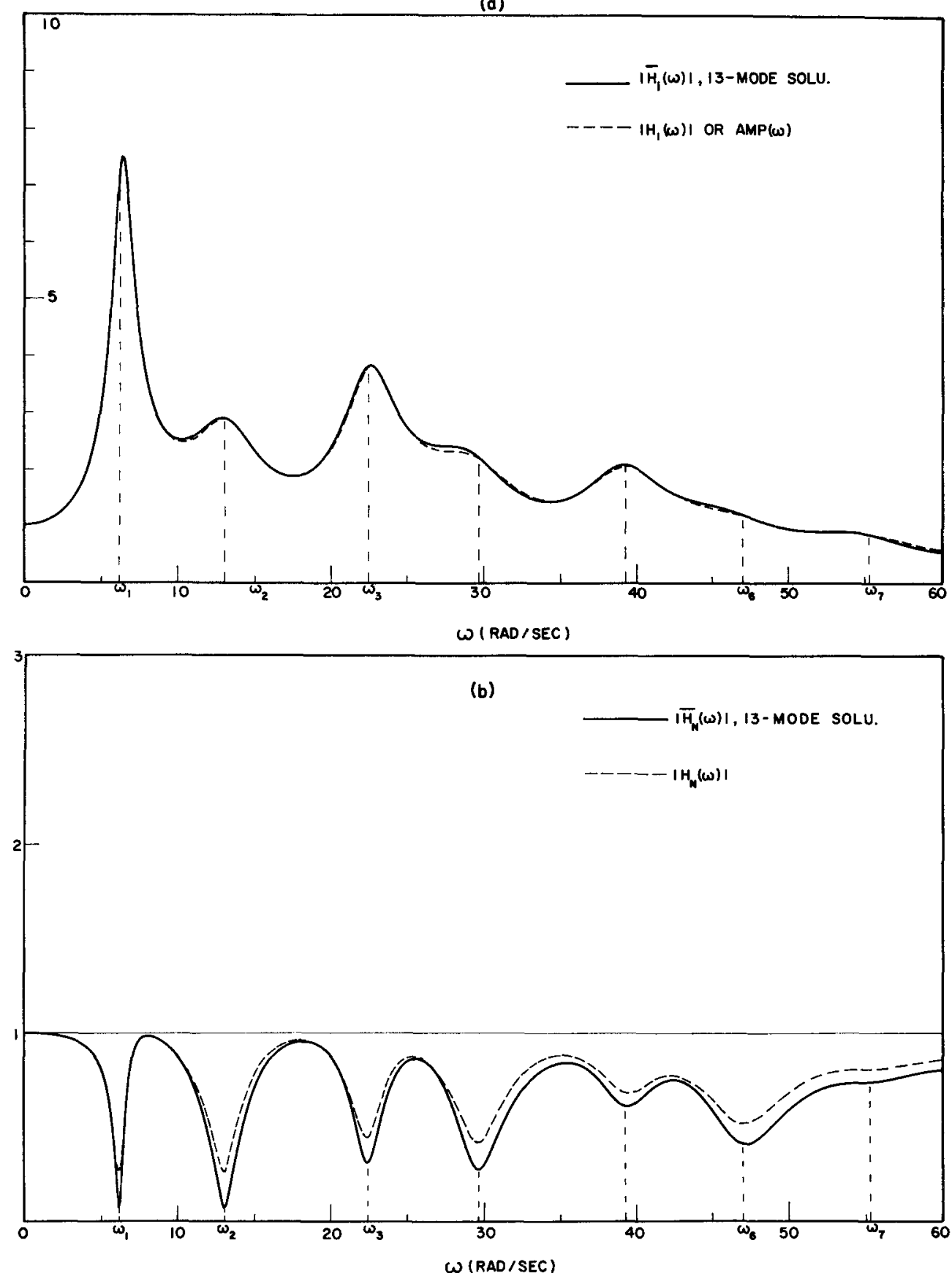

FIg. 7. The 13-mode amplitude transfer functions of the exact model (viscoelastic system).

\section{Approximate Model}

If the base impedance ratio, $\alpha_{N}$, is small the base motion will be similar to the input function, $2 y(t)$. This suggests that when $\alpha_{N}$ is small an approximate model can be used for which the base motion is the same as the input function if appropriate 


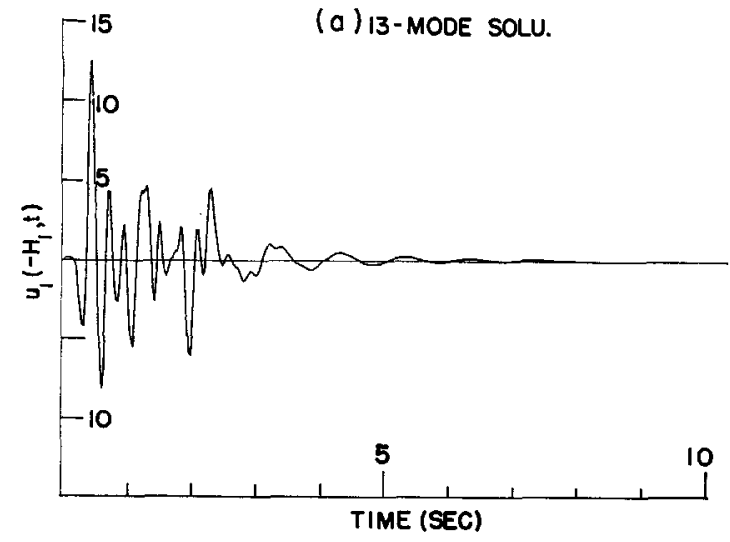

(b)

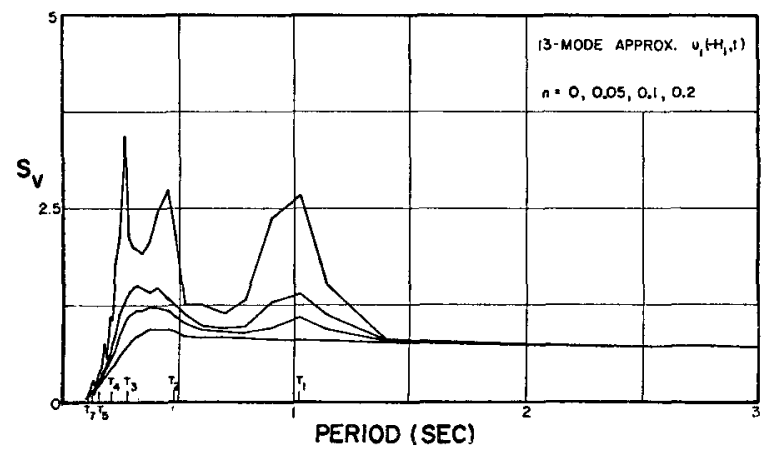

Fig. 8. The 13-mode surface motion of the exact model and the response spectrum.

damping is introduced to represent the energy that should be lost into the half-space. Such a model is obtained by replacing the dashpot $D$ in the exact model by a rigid connection while the energy that should be lost into the half-space is accounted for by incorporating an appropriate amount of viscous damping in the modes of the shear beam. The equations of motion describing this model can be deduced from equation (29a)

$$
\ddot{v}_{r}(t)+2 \beta_{r} \omega_{r} \dot{v}_{r}(t)+\omega_{r}^{2} v_{r}(t)=-2 \ddot{y}(t) \quad r=1, \cdots, S
$$

which is a system of uncoupled modal equations. Four important points should be noted:

(1) This model is only an approximate analog of a given layered system unless the actual half-space is infinitely rigid, i.e., $\alpha_{N}=0$. Hence, unless $\alpha_{N}$ is near zero, good results can be expected only at or near the surface of the layered system since near the base there is known to be a discrepancy.

(2) The values of $\beta_{r}$ in equation (40) are different from those in the exact model because of the extra damping to account for the energy that would be lost into the half-space. Consequently, for $\alpha_{N}$ not equal to zero there will always be some damping in the model even if the layers are nonviscous.

(3) Equation (40) suggests that it is better to treat the input as an acceleration, 
$2 \ddot{y}(t)$, rather than as a velocity as was done in the case of the exact model, and the response to be computed is, then, also an acceleration.

(4) The number $S$ is not necessarily the same as that used in the analysis of the exact model. Numerical calculations show that, if $\omega_{J}$ is the largest natural frequency included in the prescribed frequency range, a rule of thumb for estimating $S$ is

$$
S=J+1
$$

which is much more efficient than in the case of the exact model.

Since $\left|\bar{H}_{N}(\omega)\right|$ is assumed equal to 1 , we have

$$
\left|\bar{H}_{1}(\omega)\right|=\left|\bar{H}_{1, N}(\omega)\right|\left|\bar{H}_{N}(\omega)\right|=\left|\bar{H}_{1, N}(\omega)\right|
$$

with $\left|\vec{H}_{1, N}(\omega)\right|$ given by equation (33). The modal dampings are determined by matching $\left|\bar{H}_{1}(\omega)\right|$ with $\operatorname{AMP}(\omega)$ at each of the first $S$ natural frequencies, i.e.,

$$
\left|\bar{H}_{1}\left(\omega_{r}\right)\right|=\operatorname{AMP}\left(\omega_{r}\right) \quad r=1, \cdots, S .
$$

The iteration process used before can be used to solve equation (43) and, with $\beta_{r}$ determined, equation (40) can be solved numerically to give the surface response

$$
\ddot{u}_{1}\left(-H_{1}, t\right) \approx \sum_{r=1}^{S} D_{r}^{(1)}\left(-H_{1}\right) \ddot{v}_{r}(t)+2 \ddot{y}(t)
$$

Since equation (40) represents an uncoupled system of equations, each modal equation can be solved independently and a significant reduction in the computing time required is made.

(1) Example-nonviscous layered system. The accuracy of the approximate model will be demonstrated by again considering the nonviscous four-layered system. With $J$ equal to $7, S$ is taken to be 8 . With a maximum iterative error of 1 per cent imposed, the appropriate values of $\beta_{r}$ were obtained after only two iterations. The results are given in column 3 of Table 2 .

TABLE 2

Modal Dampings, $\beta_{r}$ (Per Cent)

\begin{tabular}{rcrr}
\hline $\begin{array}{c}\text { 1. Modal No. } \\
r\end{array}$ & $\begin{array}{c}\text { 2. Viscoelastic } \\
\text { System (Extract } \\
\text { Model) }\end{array}$ & $\begin{array}{c}\text { 3. Nonviscous } \\
\text { System (Appoxi- } \\
\text { mate Model) }\end{array}$ & $\begin{array}{c}\text { 4. Viscoelastic } \\
\text { system Approxi- } \\
\text { mate Model) }\end{array}$ \\
\hline 1 & 0.604 & 10.753 & 11.366 \\
2 & 1.109 & 14.525 & 15.466 \\
3 & 2.333 & 4.875 & 6.956 \\
4 & 2.664 & 6.811 & 9.182 \\
5 & 4.273 & 2.178 & 5.993 \\
6 & 3.916 & 5.359 & 9.154 \\
7 & 6.270 & 0.576 & 5.850 \\
8 & 6.088 & 1.589 & 14.272 \\
9 & 7.314 & & \\
10 & 7.416 & & \\
11 & 9.926 & & \\
12 & 8.940 & & \\
13 & 10.275 & & \\
\hline
\end{tabular}


The 8-mode amplitude transfer function, $\left|\bar{H}_{1}(\omega)\right|$, is compared with the exact solution, $\operatorname{AMP}(\omega)$, in Figure $9(\mathrm{a})$. There is a maximum deviation of 10 to 15 per cent at the valleys of the transfer functions. The value of $\alpha_{N}$ for the layered system is 0.506 , and although this is not a small value the accuracy of the analysis is considered ac-

(a)
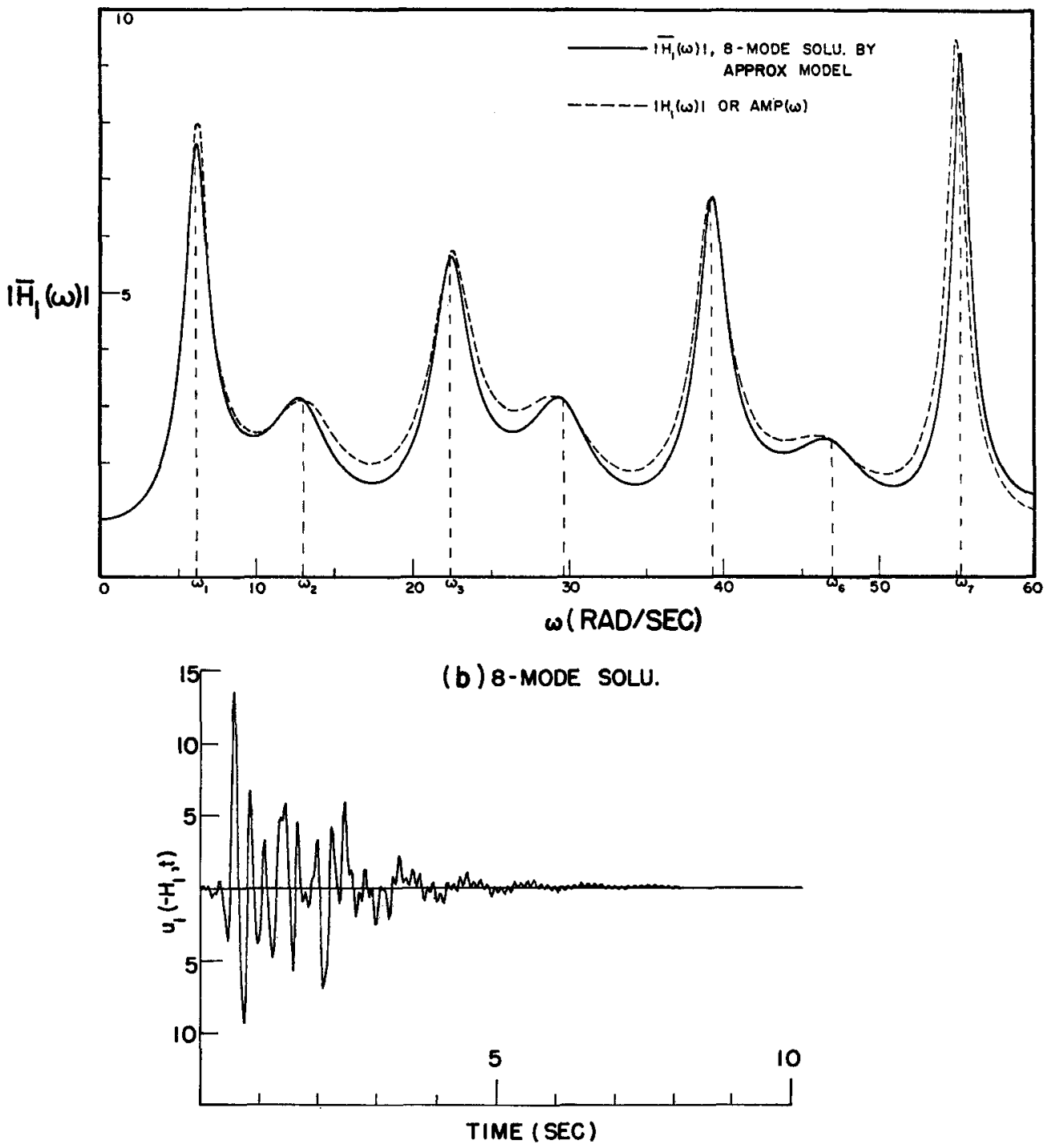

FIG. 9. Amplitude transfer function and the 8-mode surface response computed from the approximate model (nonviscous system).

ceptable. For layered systems that have a smaller $\alpha_{N}$ the accuracy will increase. On the other hand, the accuracy would not increase appreciably even if a number $S$ larger than that given by equation (41) were to be used, because the modal equations are uncoupled and, hence, the modal interaction is greatly reduced.

Using the motion shown in Figure 4 (a) as the input, the computed surface response is shown in Figure $9(\mathrm{~b})$. 
(2) Example-viscoelastic layered system. For the viscous four-layer system, the values of modal damping are listed in column 4 of Table 2 . The 8-mode transfer function, $\left|\bar{H}_{1}(\omega)\right|$, is shown in Figure $10(\mathrm{a})$. It is seen that the accuracy is better than in the case of the nonviscous system. The reason for this is that at higher frequencies the

(a)
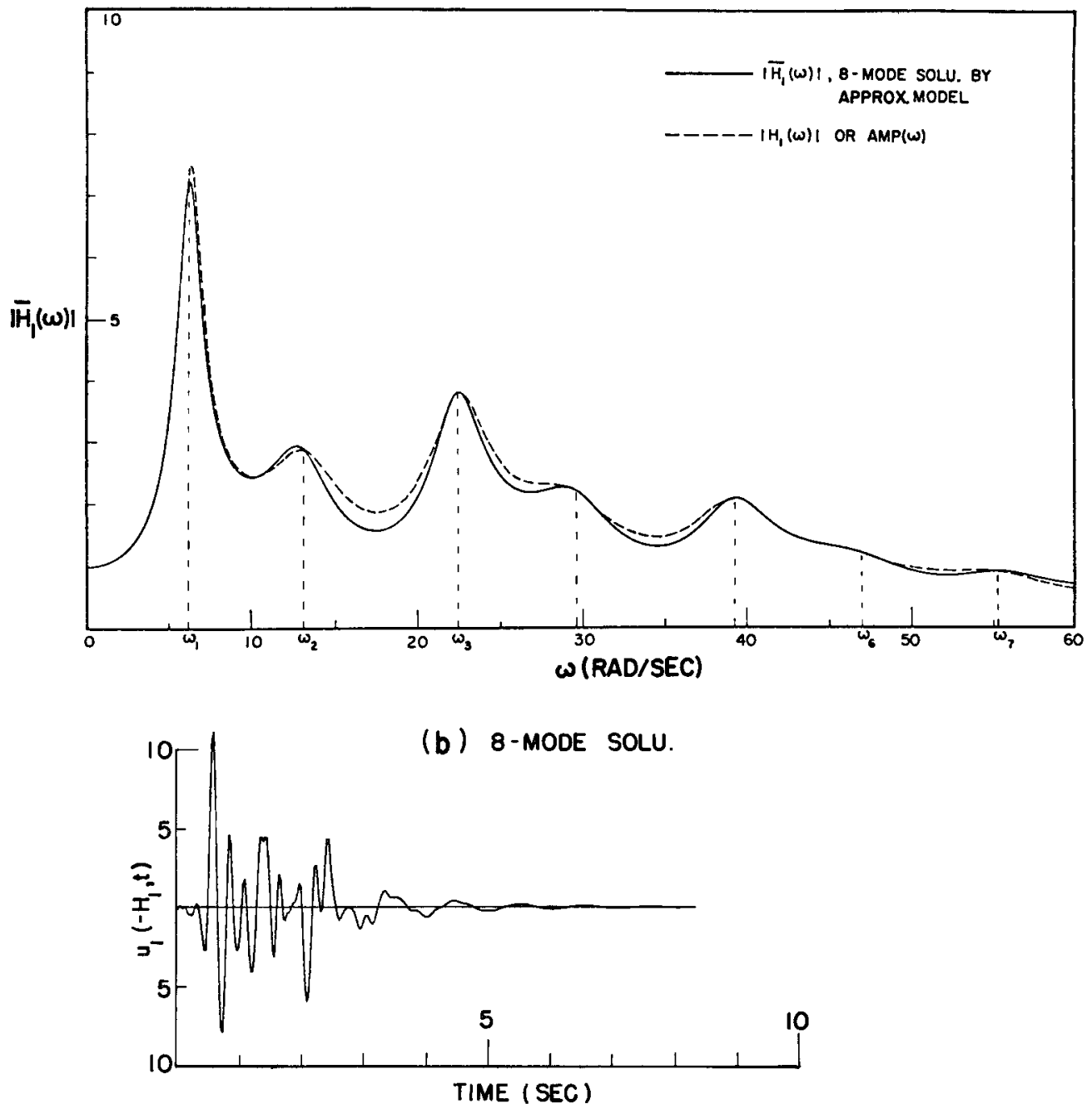

FIG. 10. Amplitude transfer function and the 8-mode surface response computed from the approximate model (viscoelastic system).

base transfer function for the viscoelastic system is closer to unity than for the nonviscous system. Using the motion shown in Figure 4(a) as input, the computed surface motion, shown in Figure 10(b), is seen to have good accuracy when compared with Figure 8(a).

\section{Analysis of the Motion Under Union Bay}

The Union Bay project, described in $R$. H. Thomson Expressway Crossing of Union Bay, Seattle, Washington (1965), collected data for the construction of a planned 
traffic tube beneath the bay. Records were obtained from three downhole seismometers of the seismograph system installed in the bottom of Union Bay in Seattle by Teledyne Earth Sciences Division. Figure 11 is a reproduction from $R$. H. Thompson Expressway Crossing of Union Bay, Seattle, Washington (1965) of the geological profile in the northsouth direction. A submerged layer of very soft, brown, fibrous peat $55 \mathrm{ft}$ thick rests
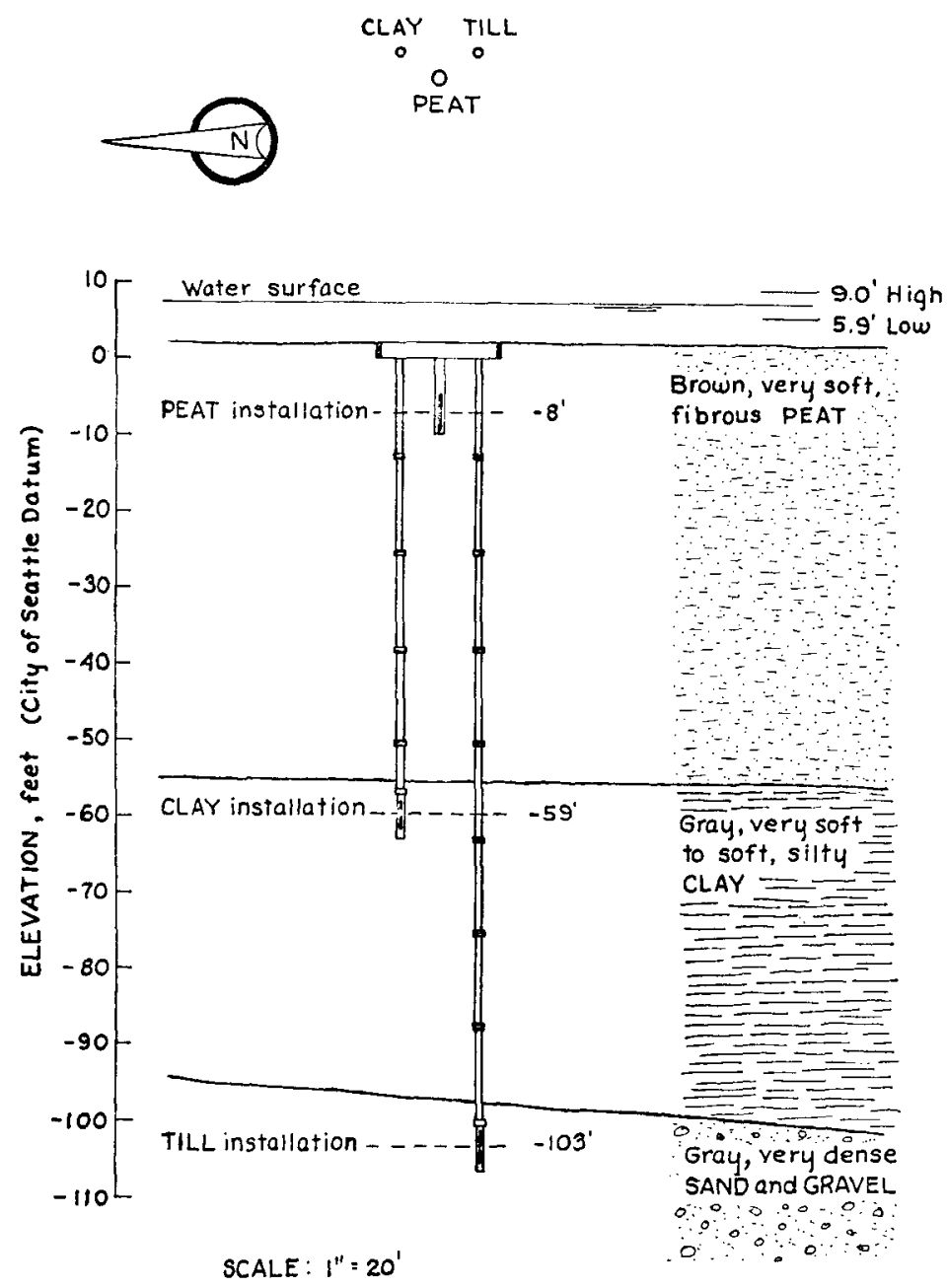

FIG. 11. Geological profile under Union Bay.

on a clay layer about $45 \mathrm{ft}$ thick containing gray, very soft to soft silty clay. Under the clay layer is glacial till composed of very dense sand and gravel. The three seismometers were installed in the middle of the bay at different elevations, one at $-8 \mathrm{ft}$. beneath the surface of the peat, one at $-58 \mathrm{ft}$. in the top of the clay, and one at $-103 \mathrm{ft}$. in the top of the till. A summary of the experimental data on the subsoil properties, as determined by Shannon and Wilson, Inc., the soil mechanics consultants, is given in Table 3 .

Two records were used in this analysis. The first one, a small local earthquake 
TABLE 3

\begin{tabular}{|c|c|c|c|}
\hline Medium & $\begin{array}{c}\text { Average Unit } \\
\text { Weight } \\
\text { (pci) }\end{array}$ & $\begin{array}{c}\text { Compressional } \\
\text { Wave Velocity } \\
c_{p}(\mathrm{fps})\end{array}$ & $\begin{array}{c}\text { Dynamic Modulus of } \\
\text { Elasticity } \\
E \text { (psi) }\end{array}$ \\
\hline Peat & 63.7 & 500 & $300-800$ \\
\hline Soft clay & 100. & & \\
\hline Medium clay & 110. & $3000-3600$ & $3000-10,000$ \\
\hline Stiff clay & 128. & & \\
\hline Till & 135. & $4600-7300$ & Not available \\
\hline
\end{tabular}

(magnitude 4.4) on March 6 1967, had a large initial pulse followed by several seconds of smaller motion which merged into the background microtremors. There was a maximum horizontal acceleration of $0.0072 \mathrm{~g}$ in the clay records which corresponds approximately to a shear strain of 0.00001 and a shear stress of 0.05 psi. The epicenter was located about 20 miles to the northwest of the recording station, with an estimated focal depth of the same order of magnitude as the epicentral distance. This situation is favorable to having the incident waves arriving with nearly vertical directions of travel. The traces of the NS and EW components of the first $10 \mathrm{sec}$ of the ground acceleration recorded in the clay and till are shown in Figure 12. The peat acceleration, of which the traces are not shown, was extremely weak and had a maximum amplitude of about $\frac{1}{6}$ that of the till motion.

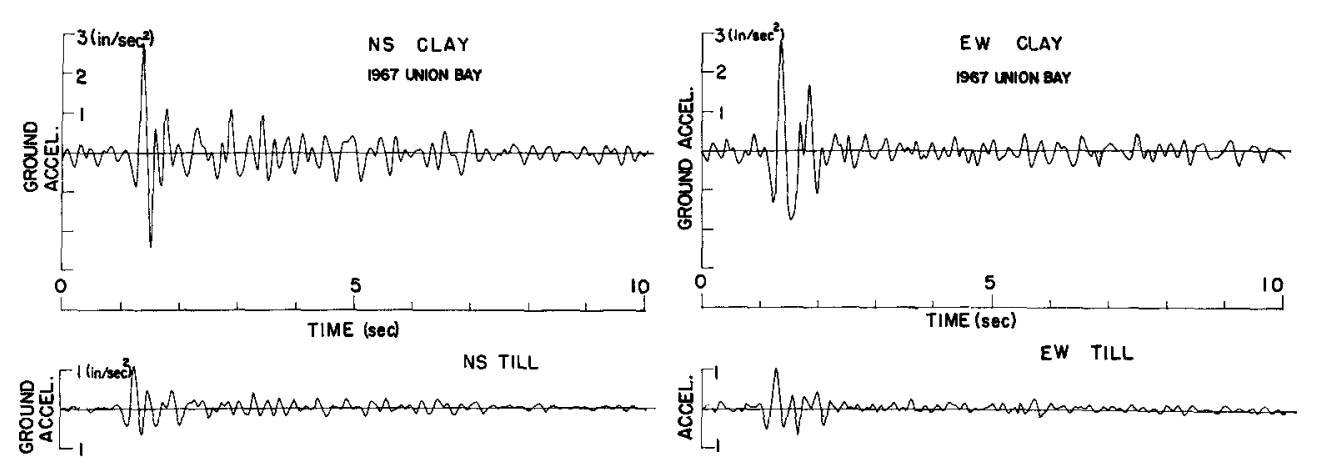

Fig. 12. The Union Bay local earthquake (1967).

The second record, obtained on December 23 1969, was a strong microtremor background noise from a local storm. Shown in Figure 13 are 8-sec-long segments of the NS and $\mathrm{EW}$ components of the clay and till motions. The clay accelerations had an averaged maximum amplitude of $\frac{3}{4} \mathrm{in} / \mathrm{sec}^{2}$ or $0.0019 \mathrm{~g}$. The peat motion, which is not shown, was essentially composed of wave components of 0.6 -sec or longer period which are long compared with those of the dominant wave components of the clay motion.

Calculations showed that the peat layer was so extremely soft that it had a negligibly small influence on the motion of the clay layer and, therefore, it was neglected and the system of clay on till was analyzed. The true values of wave velocities and damping were not known for the clay and till but approximate values and upper and lower bounds could be established. Comparison of the recorded clay motion and till motion 
also gives some information on the properties of the system, and the experimentally determined transfer function, defined as the ratio of clay to till Fourier amplitude spectra, also gives information. Shown in Figure 14, (a) and (b), are, respectively, the NS and the EW components of the Fourier amplitude spectra of the recorded clay and till motions of the 1967 earthquake. Smoothed, experimentally determined transfer
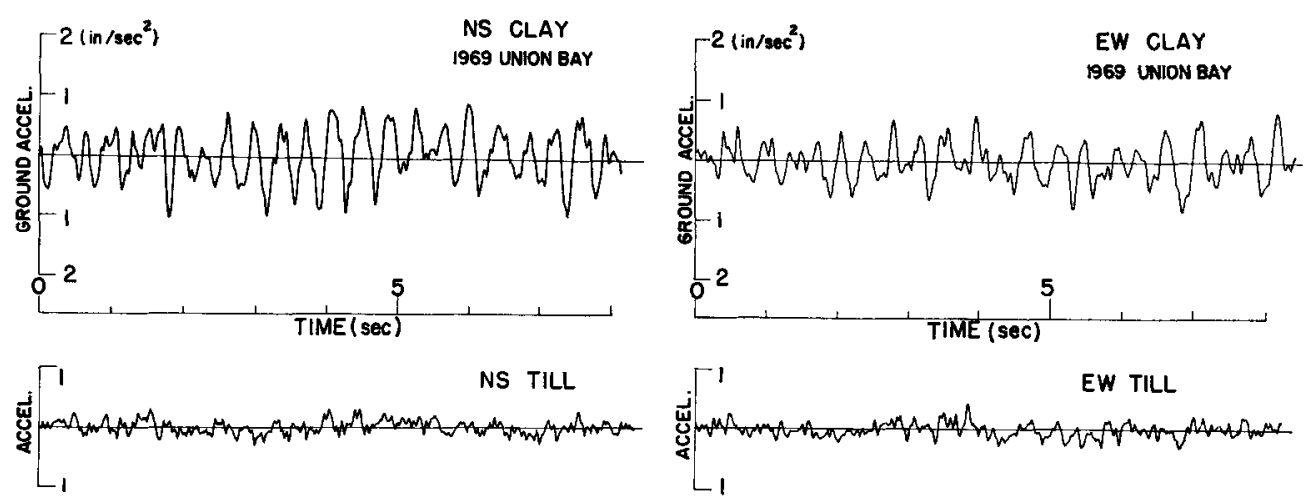

Fig. 13. The Union Bay microtremor (1969).

(a)

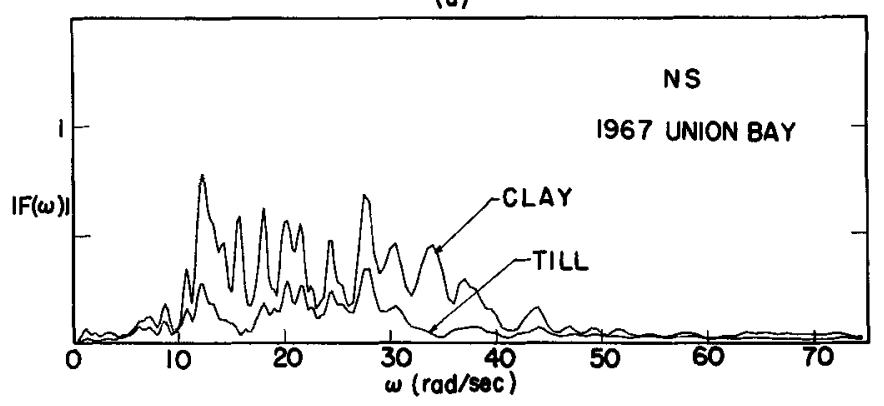

(b)

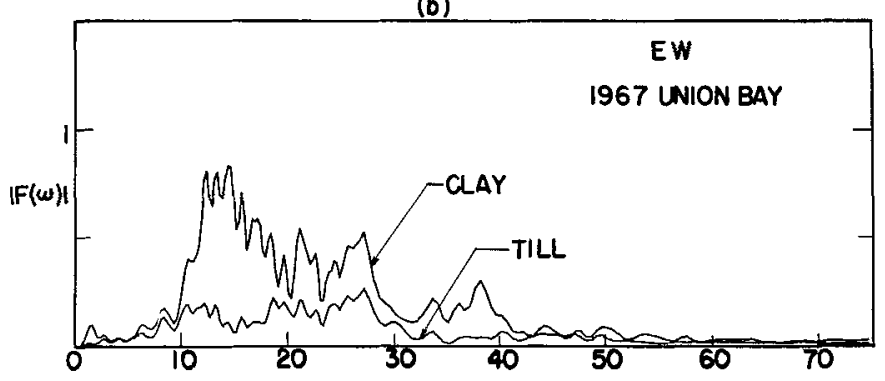

Fig. 14. Fourier amplitude spectra (1967).

functions, $|H(\omega)|$, are shown in Figure $15(\mathrm{a})$. The two peaks at 15 and 35 radians/sec in each transfer function indicate the first two natural frequencies of the clay-till system and these must be matched by the shear-beam model. Also, it can be expected that the wave velocities in the lower part of the clay will be greater than in the upper part. For example, wave velocity measurements in the clay layer beneath San Francisco Bay showed shear-wave velocities ranging from $300 \mathrm{ft} / \mathrm{sec}$ near the top to about 700 
$\mathrm{ft} / \mathrm{sec}$ near the bottom, the thickness of the layer being approximately twice that at Union Bay. From the soil mechanics data given in Table 3 it was concluded that the shear-wave velocities in the clay layer are in the range of 200 to $500 \mathrm{ft} / \mathrm{sec}$. The impedance ratio between the clay and till was estimated to be in the range 0.08 to 0.20 . Since the stresses in the clay were very small, the damping in the clay could be expected to be small also. Exploratory calculations were made with different numbers of layers, different wave velocities and damping, and the results were compared with the recorded motions. It was found that the best results were given by the five-layer model shown in Figure 16 with slightly different wave velocities for the two components of the 1967 tremor.

(a)
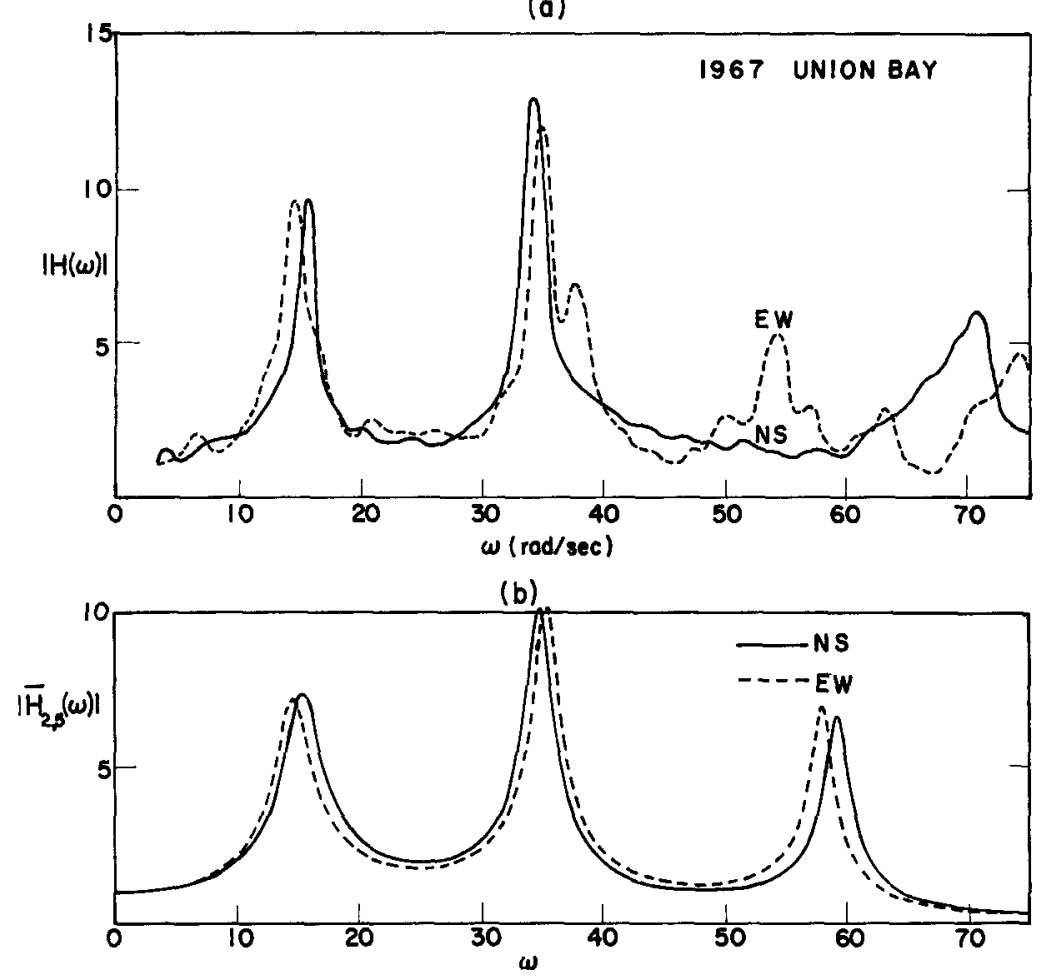

FIG. 15. Experimental and theoretical transfer function of the clay-till system (1967).

The motion at the top of the till is the base motion $\ddot{u}_{5}(o, t)$; the input function, $2 \ddot{y}(t)$, is not known. The problem, then, is, given the recorded base motion, to adjust the parameters of the system to give the best agreement between the recorded and computed clay motion, $\ddot{u}_{2}\left(-H_{2}, t\right)$. In this case, since the half-space does not enter explicitly, the exact and the approximate shear-beam models are the same. Calculations were made using the first three modes of the shear-beam model, and the best fit was obtained by the parameters shown in Table 4.

Since the base motion consisted of a large pulse followed by a train of weaker motions, the computed clay motion would also consist of a large pulse followed by weaker motion for practically any chosen model of the system. The goodness of the model must, therefore, be judged by how well the details of the motion agree. Using the 
parameters of Table 4 , the transfer function, $\left|\bar{H}_{2,5}(\omega)\right|$, was computed for each component of motion of the 1967 tremor, as shown in Figure 15(b). It is seen that there is somewhat better agreement with the recorded motion in the NS component.

The two components of computed clay motion are shown in Figure 17 where they are compared with the recorded motions, shown dotted. There is reasonably good agreement in wave shape and amplitude between the computed and recorded motions, with better agreement in the NS component. It may be noted that Seed and Idriss

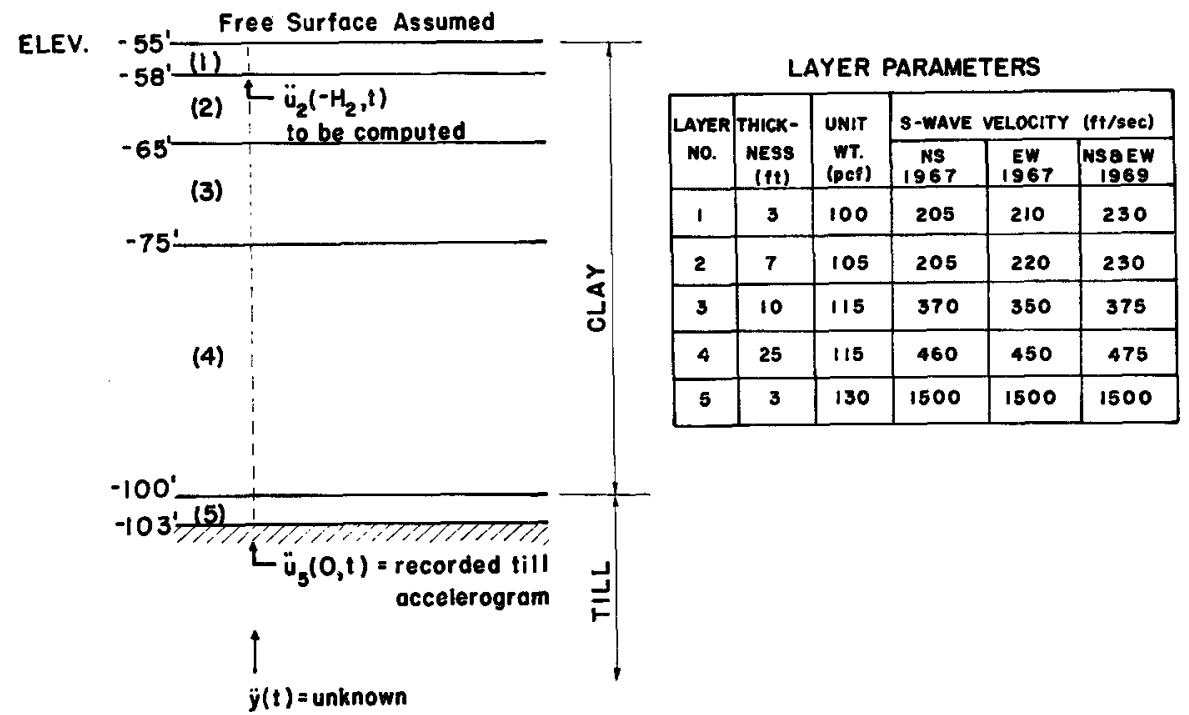

FIG. 16. The 5-layer model for the clay-till system under Union Bay.

TABLE 4

Modal Parameters of the 5-Layer Model

\begin{tabular}{|c|c|c|c|c|c|c|c|}
\hline \multirow{2}{*}{$\begin{array}{c}\text { Model } \\
\text { No. } \\
r\end{array}$} & \multirow{2}{*}{$\begin{array}{l}\beta_{r} \\
(\%)\end{array}$} & \multicolumn{2}{|c|}{ NS (1967) } & \multicolumn{2}{|c|}{$\mathrm{EW}(1967)$} & \multicolumn{2}{|c|}{ NS \& EW (1969) } \\
\hline & & 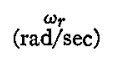 & $D_{r}^{(2)}\left(-H_{2}\right)$ & $\left(\begin{array}{ll}\mathrm{rad}_{r} \\
\mathrm{sec}\end{array}\right.$ & $D_{r}^{(2)}\left(-H_{2}\right)$ & $\stackrel{\omega_{r}}{(\mathrm{rad} / \mathrm{sec})}$ & $D_{r}^{(2)}\left(-H_{2}\right)$ \\
\hline 1 & 10.0 & 15.3 & 1.47 & 14.5 & 1.44 & 16.0 & 1.44 \\
\hline 2 & 3.0 & 34.8 & -0.62 & 35.3 & -0.62 & 37.2 & -0.61 \\
\hline 3 & 1.5 & 59.3 & 0.20 & 58.0 & 0.21 & 62.6 & 0.20 \\
\hline
\end{tabular}

(1970) have carried out similar calculations on the 1967 Union Bay motion using a lumped mass model and a different way of determining parameters.

For the 1969 microtremor similar calculations were made. The Fourier amplitude spectra are shown in Figure 18, (a) and (b), while the transfer functions, after being strongly smoothed, are shown in Figure 18(c). The experimentally determined transfer functions are not as well-defined as the ones for the 1967 earthquake and, hence, the same layer parameters have been used in the analysis for both components of motion because calculations showed that, in this case, using different parameters for each component does not produce significant improvement. Using the parameters shown in Figure 16, the 3-mode transfer function is shown in Figure 18(d) with the modal parameters given in Table 4 . It may be noted that, to obtain a better fit, wave velocities 
about 5 to 10 per cent higher than those used for the 1967 motion were used in the analysis. The computed clay motion is shown in Figure 19. Reasonably good agreement with recorded motion is observed with somewhat better agreement for the NS com-
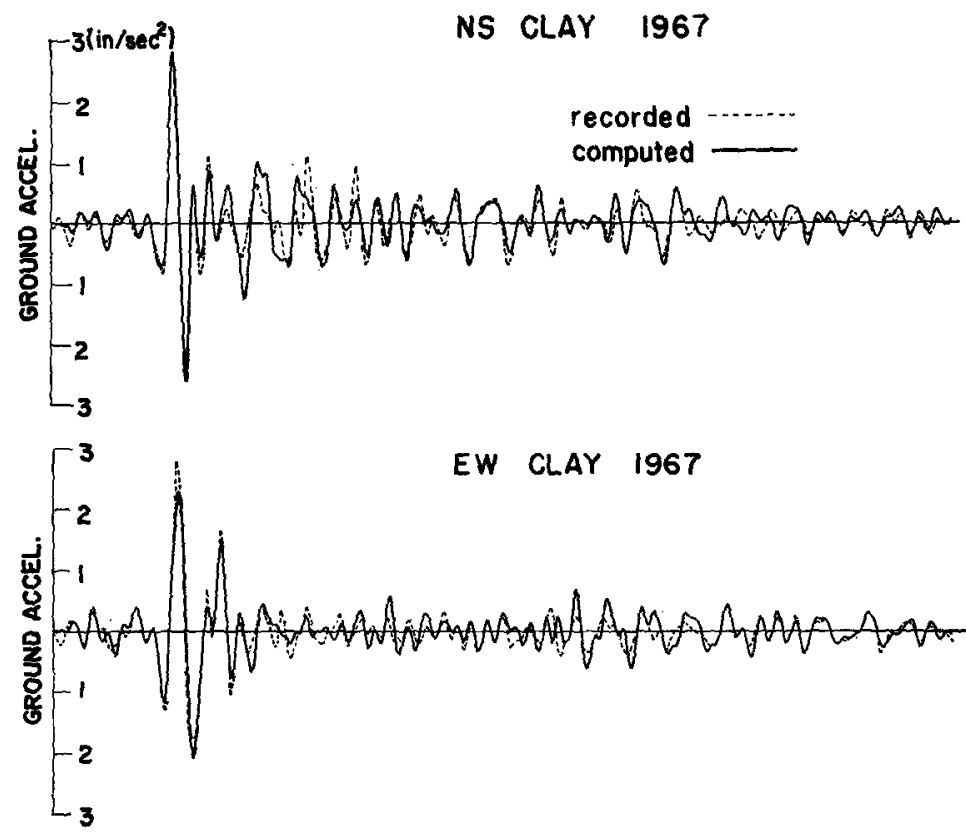

FIG. 17. Computed clay motions (1967).

(a)

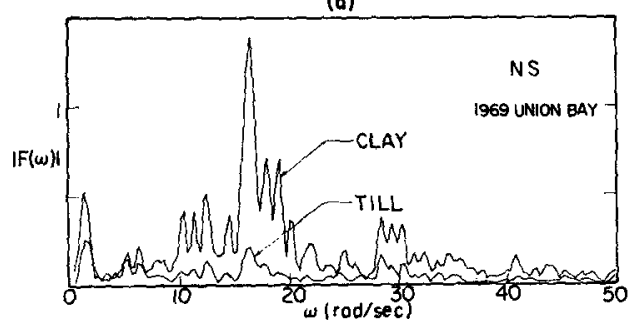

(b)

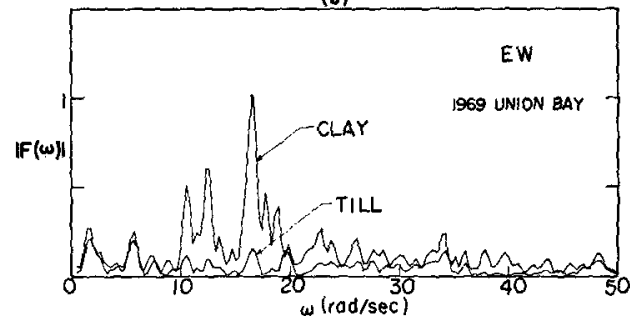

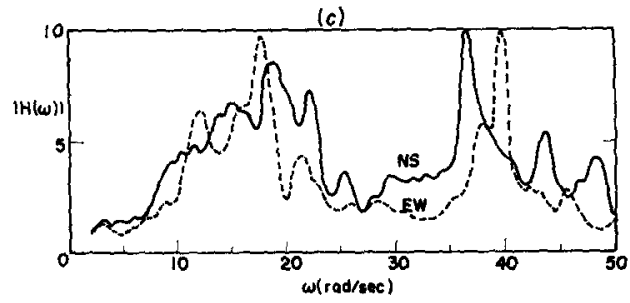

(d)

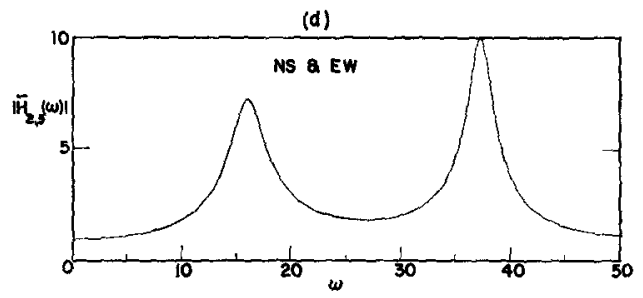

FIG. 18. Fourier amplitude spectra and transfer functions of the clay-till system (1969).

ponent than for the $\mathrm{EW}$ component. The large discrepancy observed for the first quarter-second results from the fact that in the calculations the system started from rest at $t=0$ but this transient error was rapidly attenuated by the damping. As a further comparison, the 2 and 10 per cent damped velocity response spectra, $S_{v}$, were 

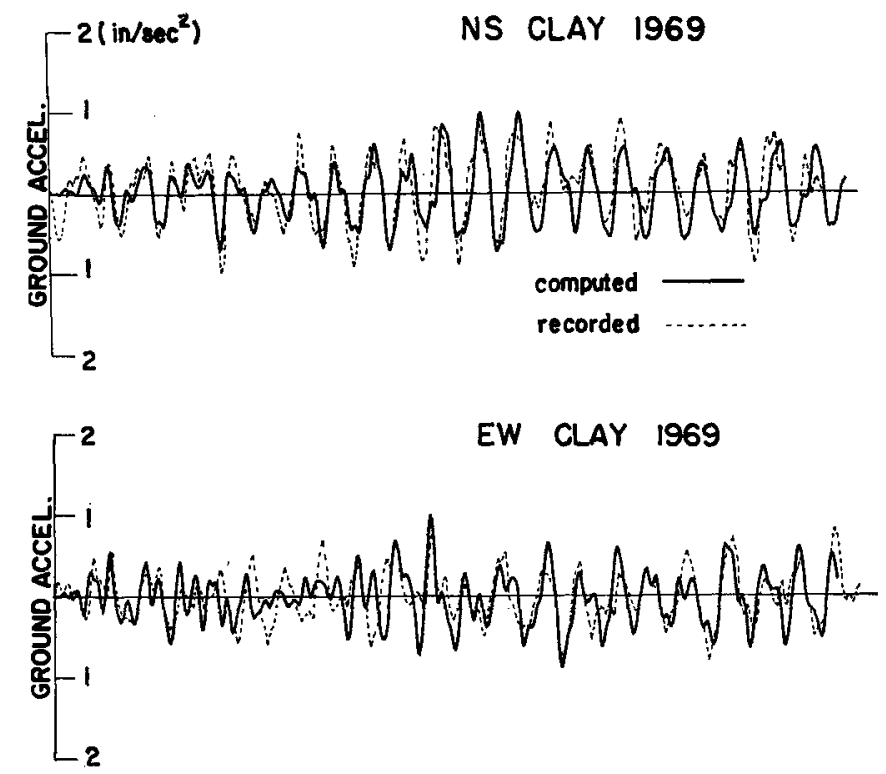

Fig. 19. Computed clay motions (1969).
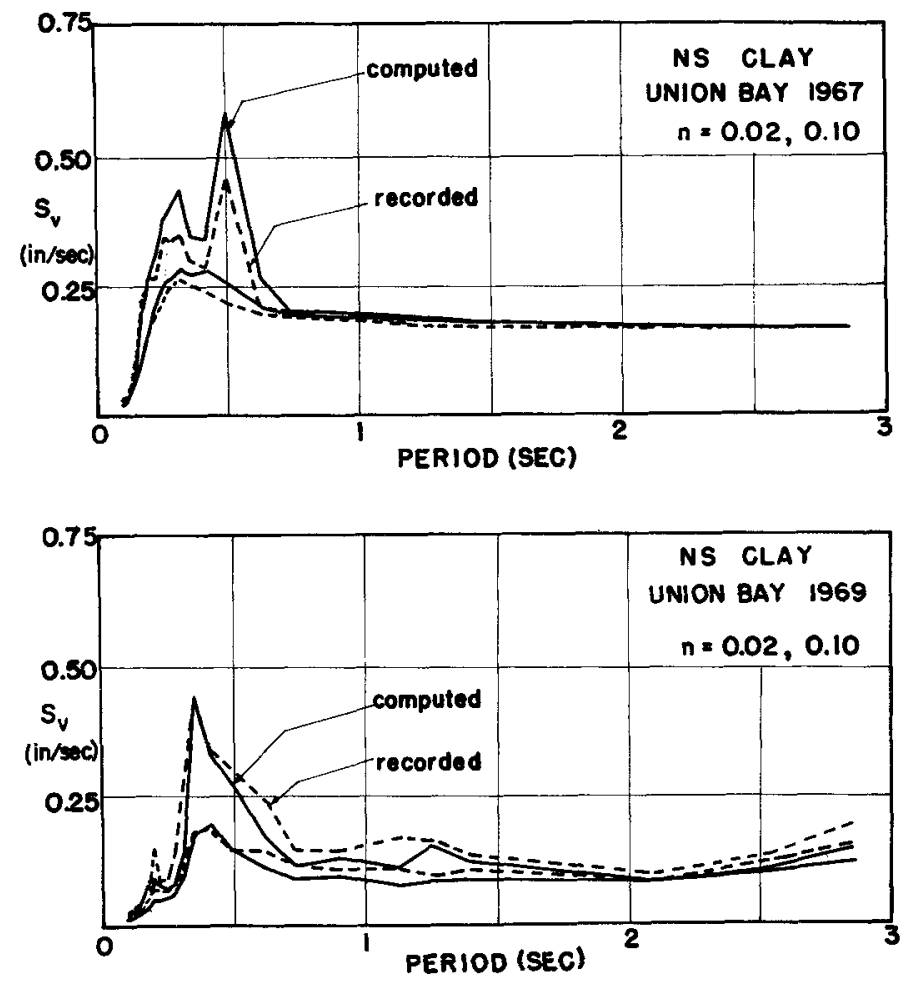

FIG. 20. Response spectra of the clay motions.

calculated for the NS component of the computed and recorded clay motions, shown in Figure 20 for both tremors.

Although the general agreement between computed and recorded clay motions is reasonably good, which it should be as all the parameters were adjusted to give the best 
fit, there are still appreciable errors in the details of the motion. We feel that the agreement cannot be significantly improved by further adjustment of wave velocities or damping. The discrepancies, we think, result from the fact that the waves are not ideal vertically-traveling, planar, shear waves, and that clay and till are not exactly planar. This conclusion is reinforced by the fact that 10 per cent of critical damping in the first mode was required to obtain the best agreement. At the very small levels of stresses and strains involved the effective viscous and hysteretic damping in the clay should be very small and, it is thought, could not account for the 10 per cent damping required in the first mode. If the actual motions are not caused by perfect verticallytraveling, planar, shear waves, extra modal damping will be required to account for energy lost from observation because of horizontal components of wave velocities. Allam (1969), on the basis of microtremor readings with arrays of instruments, concluded that waves of Love and Rayleigh types are prominent. In fact, the agreement between computed and recorded Union Bay motions is better than would be anticipated from Allam's work. There are surprisingly large differences between the amplification spectra of the earthquake and the microtremor, and the differences may be even larger for strong earthquake motions. It is not known how accurately the surface motion could be calculated from recorded earthquake base motion for a more complicated layered system in which the total depth of layering is greater than under Union Bay and the free surface motion is not available for adjusting parameters.

\section{Conclustons}

An exact and an approximate computational model have been presented for digital transient analysis of a set of linearly viscoelastic layers on an elastic half-space with vertically-traveling waves. Numerical examples exhibit the accuracy of calculated surface motion from the half-space motion. The exact model can achieve any desired degree of accuracy but considerable computing time is required. The analysis of the approximate model is much simpler and quicker but it is usable only when the impedance ratio between the bottom layer and the half-space is not large. It was observed that prominent peaks in the spectrum of the surface motion can be produced either by strong frequency components in the input motion or by a resonant amplification of a mode of the system, as indicated by the transfer function. Both models can be extended to studying the analogous problem of structure-foundation interaction.

A microtremor and a local earthquake record obtained under Union Bay in Seattle were analyzed, and the calculated motions were compared with the recorded motions. Reasonable agreement was obtained, and the discrepancies were attributed chiefly to deviation from planar, vertically-traveling waves.

\section{ACKNowLEDGMENTS}

We are indebted to the State of Washington Highway Department, to the City of Seattle, and to Worthington-Christiani-Fenco for the recordings under Union Bay, to Mr. George Kjerbol of Worthington-Christiani-Fenco for ancillary information, and to Shannon and Wilson, Inc., for information about soil properties. The sub-bay recording system is being operated by the University of Washington seismograph station and we are indebted to Dr. Norman Rasmussen for the microtremor records and other information. The study was partly sponsored by the Engineering Division of the National Science Foundation.

\section{References}

Allam, A. M. (1969). An Investigation into the Nature of Microtremor through Experimental Studies of Seismic Waves, University of Tokyo. 
Baranov, V. and G. Kunetz (1960). Film synthetique avee reflexions multiples theorie et calcul pratique, Geophys. Prospecting 7, 315-325.

Idriss, I. M., and H. B. Seed (1967). Response of Horizontal Soil Layers During Earthquakes, Soil Mechanics and Bituminous Material Research Laboratory, University of California, Berkeley.

Luco, J. E. (1969). Dynamic interaction of a shear wall with the soil, Proc. Am. Soc. Civil Engrs., J. Eng. Mech. Div. 95, 333-346.

R. H. Thomson Expressway Crossing of Union Bay, Seattle, Washington (1965). WorthingtonChristiani-Fenco, a Joint Venture.

Seed, H. B., and I. M. Idriss (1970). Analysis of ground motions at Union Bay, Seattle during earthquakes and distant nuclear blasts, Bull. Seism. Soc. Am. 60, 125-136.

Sezawa, K., and K. Kanai $(1930 ; 1932)$. Possibility of free oscillations of strata excited by seismic waves, Bull. Earthquake Res. Inst., Tokyo Univ. 8, 1-11; 10, 1-18 and 273-298.

Sezawa, K., and K. Kanai (1935). Decay constant of seismic vibrations of a surface layer, Bull. Earthq. Res. Inst., Tokyo Univ. 13, 251-265.

Trorey, A. W. (1962). Theoretical seismograms with frequeney and depth dependent absorption, Geophysics 27, 766.

Tsai, N. C. (1969). Influence of local geology on earthquake ground motion, Ph.D. Thesis, California Institute of Technology, Pasadena.

Whitman, R. V. (1968). Effect of Local Soil Conditions upon Seismic Threat to Nuclear Power Plant; Report prepared for Stone and Webster Eng. Corp.

Zeevaert, L. (1964). "Strong ground motions recorded during earthquakes of May the 11th and 19th, 1962 in Mexico City," Bull. Seism. Soc. Am. 54, 209-251.

Division of Engineering and Applited Science

California Institute of Technologt

Pasadena, California 91109

Manuscript received April 281970 